\title{
INSTRUMENTAL TOUCH: A FOUCAULDIAN ANALYSIS OF WOMEN'S FITNESS
}

\begin{abstract}
Group Pilates classes in commercial fitness gyms are among the most common forms of mindful fitness in Warsaw. The instructors teaching these classes often correct the participant's posture by touching them. While academic publications often critique fitness as a disciplinary practice, much fewer studies analyse touch understood as one of disciplinary techniques. Similarly, little is known about the experiences of fitness culture participants who encounter instrumental touch during Pilates classes. This qualitative research project analyses how Michel Foucault's concept of anatomopolitical power intersects with instrumental touch applied during Pilates classes to study how touch is used to train fitness bodies and how instructors and other participants of Pilates sessions participate in power relations. The article considers the value of instrumental touch in the context of relations between instructors and their clients.
\end{abstract}

Keywords: body, disciplinary technique, fitness, instrumentality, Pilates, touch

\section{INTRODUCTION}

Multi-dimensional fitness gyms are often 'promoted as social spaces where individuals can transform body—self identities' (Brighton et al. 2021: 45). They offer their clients a range of physical fitness practices, as well as knowledge and expertise facilitating the development of various body projects. Fitness gyms are also frequently described as disciplinary institutions, in which various disciplinary body practices are embedded (e.g. Markula and Pringle 2006; Greif 2017). Lastly, gyms constitute important physical and cultural spaces where the bodies of clients are touched in a specific manner and for specific purposes. They are also spaces where instructors use touch, imbuing touch practices with specific meaning and initiating their own creative uses of touch. Thus, fitness clubs appear to be the right environment to examine the policy of touch.

The present analysis focuses on touch used by fitness instructors during Pilates classes. The results of the research presented below indicate that Pilates classes involve relatively frequent touching. The issue of how to touch participants during training is also discussed during courses for Pilates instructors, although it is only done as an aside when tackling other topics. This study examines how the kind of touch that will, for the purposes of the analysis, be referred to as 'instrumental', operates within commercial fitness gyms and through the fitness bodies that inhabit these spaces. In the context of the 
present analysis, touch has been positioned as a social practice. The study also analyses how Michel Foucault's concept of anatomopolitical power intersects with the instrumental touch applied during Pilates classes to study how touch is used to train fitness bodies and how instructors and other participants of Pilates classes participate in power relations. It considers the value of instrumental touch in the context of relations between instructors and their clients.

It should be noted that most of the data gathered during field research and presented in this study pertains to the period before the COVID-19 pandemic (even though the interviews were conducted before, during, and after the lockdown). The epidemiological situation profoundly affected the functioning of gyms, imposing numerous changes, including some pertaining to the realm of touch, so crucial in the spread of disease. The effect that the pandemic had on the methods and the experience of touch in fitness culture certainly merits a separate study in the future. ${ }^{1}$

\section{PILATES IN WARSAW: \\ THE GLOBAL INTERTWINED WITH THE LOCAL}

Fitness culture is a significant cultural phenomenon with its global/local variations (e.g. Andreasson and Johansson 2014; Hedblom 2009; Sassatelli 2000; 2011; Smith Maguire 2007; Spielvogel 2003; Volkwein 1998). In the present analysis, the term 'fitness culture' is used to denote 'the symbolic and cultural ideas that constitute a specific way of approaching the body and physical culture' (Andreasson and Johansson 2014: 13). As a global phenomenon, fitness culture is currently affected by processes of standardisation and homogenisation, at least in some of its aspects. At the same time, however, it is dependent on local traditions, which contain models of heterogenisation and diversity (e.g. Spielvogel 2003; Steen-Johnsen 2007). Consequently, the relation between the global and the local appears to be complex, changeable, and mutual, since the local isto a greater or lesser degree-influenced by the global, and vice versa (Andreasson and Johansson 2014; see also Ram 2004). It may therefore be assumed that a scholar considering the global aspects of fitness culture should not disregard its local characteristics, as it is the latter that allow one to notice details and subtle differences without which the study of global phenomena would be incomplete and offer an overly simplified view of reality. This justifies the need to conduct in-depth ethnographic studies on fitness culture in Poland, which has not yet been examined in a comprehensive manner as a local variation of a global cultural phenomenon.

Commercial fitness practices appeared in Poland considerably later than in the United States and countries of Western Europe (e.g. Green 1986; Hedblom 2009). While the first aerobics club was established in Warsaw in 1983, the expansion of the commercial service sector (including services associated with physical culture) was only made possible by the onset of the economic and political transformation that began in 1989 (Kunicki 1997). The fitness industry truly started to develop in Poland in the 1990s and expanded gradually in the first two decades of the $21^{\text {st }}$ century. It should, however, be noted that despite this ongoing development, only $8 \%$ of Poland's residents were using the services provided by fitness centres in 2019 (European Health \& Fitness Market 2019). The latest estimates indicate that before the COVID-19 pandemic there were ca. 2,700 fitness clubs in Poland, offering membership to nearly three million people (Juś 2020). At present, the scale of the damage resulting from 
the pandemic is impossible to ascertain, yet the fitness industry is expected to be among the most affected sectors of the economy (on the situation of Polish fitness instructors during the pandemic, see Czarnecka 2021).

Fitness practices collectively defined as mindful fitness have become increasingly popular in Poland (Markula 2004). Along with yoga, Pilates, although it is still relatively new in Poland has become one of the most popular forms of mindful fitness in Warsaw. Joseph Pilates started to develop his method nearly 100 years ago (during the First World War), yet mentions of Pilates did not appear in the Polish media until ca. the year 2000. The first professional courses for Pilates instructors in Poland were organised by Iza Stasiakowska in 2001; before that date practical knowledge about this fitness method could only be acquired abroad. The most popular destinations in this context were the United States of America and Great Britain (Pilates Polska 2019).

Pilates dubbed the method he created Contrology. He understood it as

complete coordination of body, mind, and spirit. Through Contrology you first purposefully acquire complete control of your own body and then through proper repetition of its exercises you gradually and progressively acquire that natural rhythm and coordination associated with all your subconscious activities. (Pilates and Miller 1960: 9)

Professional Pilates studios offering different forms of exercise-using mats, reformers, and other kinds of equipment - may currently be found in every major city in Poland. Meanwhile, the classes organised in fitness centres are usually limited to exercising using mats. The number of participants in these sessions differs depending on the policy of the given fitness chain. Pilates classes in fitness centres are cheaper than in professional studios, and therefore accessible to a wider spectrum of consumers. Very few fitness clubs in Warsaw divide their classes into levels of proficiency. Usually a single group comprises up to around a dozen people of varying age and practical experience with Pilates. Although the classes are theoretically open to people of all genders, group classes are mostly attended by women. The few men that arrive usually come to classes only sporadically and do not exercise on a regular basis. Most of them prefer individual workouts in fitness gyms.

It should be remembered that the local context intertwines with global processes of standardisation and homogenisation. Many fitness instructors from Warsaw take part in international conferences on fitness culture and Pilates courses conducted by foreign teachers In time, some of them acquire international certificates and teach Pilates courses abroad. Likewise, at least some of the women who attend Pilates classes in Warsaw's clubs have had the opportunity to participate in similar exercises in other countries. Some of them have trained under the supervision of foreign teachers during online classes. All of these factors indicate that qualitative ethnographic research in Warsaw's fitness clubs would yield valuable data. Such studies may provide some insight into globalising fitness culture, while the analysed processes may have broader applicability to other parts of the world.

Before moving to the results, I will provide the theoretical and methodological framework of the research. 
THE THEORETICAL FRAMEWORK: FOUCAULT, DISCIPLINARY TECHNIQUES, AND DOCILE BODIES

Foucault perceived the body as the site of workings of power. He saw discipline and docility as ultimately associated with state power, yet his approach has been adopted in many different fields, including the analysis of sport and physical culture, and also in commercial contexts (e.g. Chase 2006; Clark and Markula 2017; Hanold 2010; Markula and Pringle 2006). As regards commercial fitness gyms, some scholars suggest that although the phenomenon of gym-going developed from the concept of individual, autonomous choice, 'gyms are disciplinary institutions that remove us from our liberty as the body endures work driven by contemporary discourses of health and fitness' (Greif, cited after Brighton et al. 2021: 47; see also Sassatelli 2011). Others note that commercial fitness gyms bear the characteristics of disciplinary spaces, and as such facilitate the evolution of various disciplinary techniques in which docile bodies are produced. 'Exercise classes can be seen as potential sites for disciplining individuals into docile bodies: the space, the gym, is constructed to allow disciplinary control over fit bodies' (Markula and Pringle 2006: 78).

Foucault (1995 [1975]; 2010 [1976; 1984])

was interested in various forms of modern power, believing that power is always productive and relational, that it manifests itself in all relations and practices, and that each individual has the ability to participate in power relations. He also claimed that power is not a constant property that a given individual or institution uses to oppress those who lack it. What he emphasised is that power relations are often asymmetrical and that some individuals have more ability to use their power than others (Foucault 1995; Clark and Markula 2017). In the context of the social world of fitness culture, this means that instructors do not oppress the women they are coaching, even though they remain in a specific power relation with them. Within it, the instructors are able to exercise power easier than their clients, yet the power relation is not constant and may change in time or be broken.

In his earlier works, Foucault (1995) concentrated on anatomo-political power, stating that the form of power that is exercised through disciplinary techniques is applied to produce obedient and useful bodies of individuals, which he dubbed docile bodies. According to Foucault, a body that constantly remains within specific power relations is not only affected by these relations, but also affects them. It may therefore be assumed that female fitness bodies are not oppressed or passive, but play an active role within the power relations in which they participate. Since this study examines the way in which female fitness bodies are controlled and shaped through specific practices used in the gym room, with particular focus on instrumental touch, Foucault's concept provides a useful theoretical framework. Before instrumental touch is discussed, I shall briefly present several other disciplinary techniques used in gym rooms, namely the managing of bodies through the organisation of space, time, and motion. All of these elements delimit the framework of the meetings between clients and instructors and determine the approaches to the body and - consequently - the ways in which it is touched.

\section{STRUCTURING SPACE}

Foucault claimed that anatomo-political power operates through the proper organisation of space and that disciplinary spaces are enclosed, 
functional, partitioned, and ranked (Foucault 1995: 141-146). 'In the first instance, discipline proceeds from the distribution of individuals in space' (ibid.: 141). Fitness rooms are designed to ensure that group fitness activities may proceed without external interference. Each of the participating individuals should have enough room to be able to exercise with unimpeded motions. In the case of Pilates, the space is additionally divided using mats. At the beginning of the class, the instructor stands away from the other participants, which defines and emphasises his/her role- the visibility of rank. What is more, the space of the fitness room should be arranged in such a way that the information provided by the instructor is available to the participants through various modes of expression (i.e. the face, the voice, the position of the body, verbal communication). The other participants choose their spots in the room themselves, yet the instructor may, at least to some extent, introduce changes in the configuration of fitness bodies in space.

\section{STRUCTURING TIME}

According to Foucault, individual bodies are disciplined by the organisation of not only space, but also time. Fitness centres follow schedules that delineate the start, finish, and duration of each training session. Every session is divided into segments during which specific motions are performed, which ought to harmonise with the rhythm of the accompanying music and the movements of other participants (usually the segments involve: the warm-up, the main part, relaxing/stretching). It should, however, be noted that in Pilates the motions in exercises are not performed to or determined by the rhythm of music (some instructors even conduct classes with no music involved). Likewise, the exact synchronicity of movement within the exercising group is of less importance in Pilates than in other fitness forms, e.g. the choreographic ones. The time allotted to training does not involve unnecessary breaks and is used to the maximum, in order to achieve specified goals.

\section{MANAGING BODIES THROUGH MOVEMENTS}

Foucault claimed that bodies and movements ought to be organised into segments that allow the pre-established goals to be attained. In commercial fitness gyms, each form of fitness activities involves performing different exercises. Instructors should prepare a plan in which they may, for instance, focus on building up specific groups of muscles. They may then increase the level of intensity and complexity of specific motions with each training session, taking into account the skill of the group. They may also increase the level of difficulty of the class over a longer period of time. In practice, however, because gyms are meant to provide leisure and recreation (Sassatelli 2015), anyone who paid the fee is allowed to participate in all classes, regardless of whether they have mastered the required sequences of movement or not.

In Foucault's view, the aim of disciplinary techniques is to produce docile bodies-bodies that have internalised specific movements to such a degree that they are able to perform them automatically and without hesitation. However, the present article is not concerned with the effectiveness of disciplinary techniques in producing docile bodies. What it does examine is the way in which anatomo-political power is exercised through instrumental touch used intentionally by fitness instructors during Pilates classes. Thus, it is interested in touch as one of the disciplinary techniques. 


\section{THE METHODOLOGICAL FRAMEWORK}

This study was guided by an inductive approach, which provides solutions to discover relations and patterns in the data collected (Glaser and Strauss 1967). The multi-method approach comprised four elements: (a) eleven semi-structured in-depth interviews with female fitness culture participants (recorded and transcribed), (b) observant participation (Wacquant 2004), (c) informal conversations (Hammersley and Atkinson 1995), and (d) content analysis of two training manuals. To ensure the credibility of my qualitative data, triangulation of data was applied (Creswell 2007).

The field research was conducted between March 2019 and October 2020 in three different clubs belonging to one of Warsaw's fitness chains and is grounded in multi-sited ethnography (Falzon 2016). The present analysis only presents experiences reported by female Pilates instructors and female participants of fitness classes. The focus on women's experiences may be a limiting factor, yet the choice was not accidental. Firstly, group fitness activities in Warsaw are attended predominantly by women. Secondly, since the experiencing body is socialised, there are socially and culturally determined differences in the experience of corporeality by women and men (Young 2005). Thirdly, the data and conclusions presented in this article are a part of a broader research project, in which fitness culture in Poland is analysed as a gendered phenomenon (see also e.g. Aoki 1996; Markula 1995, 2001; McKay 1994). Finally, I myself have been working for years as a fitness instructor and have therefore shared the experiences of the female members of this social world (at least to some degree). The present study is further limited by the fact that Polish society is relatively homogeneous, which is also apparent in the field of sports and mass leisure activities. Consequently, all my participants were White women.

The study is based on ethnographic qualitative methods, with the research process divided into two stages. The first step involved analysing the content of two training manuals which I had received during Pilates instructor courses. Since I had participated in these myself, I also chose to analyse the notes I had made at the time, focusing on all descriptions that in any way referred to touch in Pilates. The present article is mainly based on the findings made during the second stage of research. The eight semi-structured in-depth interviews with female fitness instructors and exercisers were face-to-face. Three interviews (two with instructors and one with a client) were conducted online via the Skype platform. All the interviewees (five fitness instructors and six participants of Pilates classes) were White women between 35 and 89 years of age. For the sake of anonymity, the names appearing in the article have been changed. Due to the asymmetrical power relations during Pilates classes in the commercial fitness gym (Foucault 1995; Markula 2004), the study focused mainly on instructors. Principally, it is they who initiate instrumental touch. They can be also key creators of change. As a fitness instructor familiar with social world of fitness culture participants, I was able to personally participate in touch practices in fitness gyms, both as a coach and as a participant of Pilates classes taught by other instructors. My participation in Pilates classes in both these capacities resulted in the collection of video recordings and notes which I typed after every class and saved on my personal computer. All my respondents were given prior information about the objectives of my research and participated in it willingly. 
THE SPECIFICITY OF INSTRUMENTAL TOUCH

One of the first scholars to explore the sensory aspect of experience in sports practices was Loïc Wacquant (2004). It should also be noted that significant contributions to the study of sensory dimensions of sport and physical activity were made by works in the field of cultural history of the senses, including the gendering of (Classen 1993, 2005; Classen et al. 1994) and the anthropology of the senses (Howes 2003, 2005; Pink 2009; Vannini et al. 2012), even if they did not refer to sporting experiences expressly. Recent years have brought the publication of numerous works whose authors focused on the role of specific senses in sports and physical culture (e.g. Downey 2005; Hockey and Allen-Collinson 2007), with some concentrating on touch (e.g. Channon 2013; Hamilton 2017; Lewis 2000; Slavin 2003). This is hardly surprising, given that 'sports participants hear, smell, see, touch, and move within their particular sporting environments, whether hockey pitch, mountain face, ice-rink, or squashcourt' (Hockey and Allen-Collinson 2007: 123). Although this is beyond the scope of the present analysis, it might be added that an increasingly large number of studies focusing on the senses in sports practices make use of the auto-ethnographic method, in which the researcher's body is regarded as the main 'instrument' of sensual data collection (Sparkes 2016; Czarnecka 2020). The scarce mentions of touch that may be found in publications on fitness culture are, at best, added as an aside to the main line of argument (e.g. Andreasson and Johansson 2014). Thus, conducting in-depth ethnographic studies on the matter seems all the more justified.

In practice, the environment of a fitness gym is conducive to many different types of touch. Not all of it is intentional; in many cases touch is accidental and simply results from momentary lack of attention. Similarly, not all of it is authoritative or disciplinary; for instance, some of it may be a part of ordinary social relations. Lastly, not all tactile experiences in fitness pertain to the touch between human individuals. The most common example are the physical contacts between fitness bodies and objects (e.g. the floor, the walls, mats, exercise balls). Although all of the mentioned types of tactile experiences merit a detailed analysis, the present work focuses solely on instrumental touch, since it is the form that allows us to examine how the anatomo-political power operates within the space of a gym and how docile bodies are produced in the context of recreational fitness. It must be noted that, although correcting by touch is a very popular method of teaching, it is not employed by all fitness coaches during Pilates classes. For various reasons, some of them only use verbal instruction and demonstration.

The field research indicates that there are instructors (albeit not many) who pay no attention to the accuracy of their clients' movements, and thus do not use any methods of correcting mistakes. One possibility that cannot be ruled out is that instructors adopt this approach to corrective techniques because they regard all fitness forms as recreational in function (Rojek 2000; Sassatelli 2015; Stebbins 2009).

One thing may be that someone totally ignores people and never corrects them at all. Pays no attention, just exercises for him or herself, looks at the mirror and exercises. Perhaps I wouldn't even be aware of this, although I've taken part in classes, even Pilates ones, where [the instructor] simply did not correct anyone, not once. And 
I think that, okay, if such a person now comes to my classes, where I do correct, and earlier only attended classes where no-one was correcting anyone, they can be really shocked, won't they? They may think that it's something strange. But for me, this is, well, you don't go to classes to (...) so this is this one thing, that you go to classes precisely for someone to be looking at you and correcting your mistakes. And this is also the feedback I get, when someone who had never once been corrected during classes in the past comes to my class and says 'gee, how grateful I am that you did correct me. You know, I was never corrected. I never even knew I was doing something wrong.' So I know that this is needed. ${ }^{2}$

Regardless of the nature of the touch, one key factor is the duration of the physical distance between the body that touches and the one being touched. Touch belongs to contact senses, which means that it is realised through direct contact with the subject/object (in contrast with telecontact senses, which operate across space, e.g. sight or hearing) (Mizińska 2010: 83). According to Edward Hall, touch constitutes one of the coding variables within proxemics measures (1963: 1007) and depends on the type of interaction which, again, is connected with proxemic (distance) zones, each with a close and far phase. Four types of social distance may be present in a training space, yet touch based on the physical contact of two bodies takes place within personal space (1.5-4 feet), and sometimes also enters into intimate space (less than 1.5 feet). As far as fitness gyms are concerned, 'the staging of intimacy has clearly been given a culturally bound significance' (Andreasson and Johansson 2014: 58). This shall be discussed in a further section of the present study.
As a disciplinary technique which helps control and correct the operations of the fitness body, instrumental touch is based on several principles, whose application and definition is determined by the given situational context. Instructors in commercial fitness gyms touch their clients in specific ways during physical exercises. It is in this context that the meanings of instrumental touch are circulated and the related physical experiences appear. Since instrumental touch is used as a 'tool' that facilitates attaining pre-determined goals effectively, it is fully functional and instrumental in nature. At the same time, it must be both intentional and authoritative-in the case of fitness culture, instrumental touch is, as a rule, initiated by the instructor, who consciously employs it on the individuals participating in her classes. As mentioned above, instructors and their clients remain in specific power relations, in which the former exercise power more easily than the latter. This is manifested by the existence of a clear-cut boundary between the instructor, who initiates the touch and touches, and the other participants, who are touched. Asked whether situations occur in a fitness gym when it is the client that touches the instructor, one of the interlocutors answered:

Generally, no. I don't know if anyone would have the guts to touch me [laughs], or the need to, but no. (...) This is probably very one-sided, one-directional, like with a doctor or a masseur. ${ }^{3}$

In some-if rather rare-cases, clients in the fitness gym ask the instructor to touch them and check whether they are, for instance, flexing their muscles correctly or assuming the right positions (Observation journal, August 31, 2020). In the broadest sense, such 'incentives' may be regarded as instrumental touch being 
initiated by the participants of the training, and therefore as an example of fluidly negotiating the relations of power between the instructor and the client. Ultimately, however, it is the instructor that decides whether or not to acquiesce to the client's request in the given situation.

\section{THE OFFICIAL INSTRUCTIONS REGARDING INSTRUMENTAL TOUCH DURING PILATES CLASSES}

Fitness instructors acquire theoretical and practical knowledge on the policies of touch in Pilates from various sources, such as professional courses for Pilates instructors, training manuals, visual materials available online, or participation in classes taught by more experienced coaches. The issue of transmitting non-verbal/tacit knowledge, which includes 'knowledge based on sensual experience' (Jakubowska 2017: 28), certainly merits its own analysis, yet lies beyond the scope of the present study. It should, however, be emphasised that during instructor courses organised in Poland, the issue of touch is discussed very rarely or not at all. If courses provide some information regarding the principles and methods of touching clients, it is done in passing, when discussing other issues. Touch and the related experiences are not spared too much attention, which is not to mean that tactile direction is not included in the methods of teaching instructors during Pilates courses (or at least some of them).

Several basic suggestions regarding instrumental touch may be distinguished in the official instructions based on the training manuals that $I$ received in the course of professional training for Pilates instructors, and the notes I made when taking these classes. They offer clear indication on how instructors ought to be touching their clients during Pilates classes, and what behaviours to avoid:

- physical touch should be certain, exact, direct, purposeful, and confident;

- clients' permission should always be requested;

- touch should not be applied if the same effect can be achieved in another way;

- the instructor should place his/her hands firmly on the body of the client (e.g. on the arms, back, legs) and instruct the client, gently yet firmly, what is expected of him/ her;

- the sequence consists of: approaching the person, instructing through touch, moving away;

- the client cannot be touched without a warning, he/she should have an opportunity to notice the approaching instructor in advance.

Interviews with fitness instructors indicate that these instructions are mostly followed in everyday practice. It should, however, be noted that instructors' experiences may vary. Advice seems dependent on the person of the teacher conducting a given instructor course and the methods he or she used in their own practice. Asked whether the Pilates course she had taken involved any mention of the principles of touching clients, one of the interlocutors answered:

Yes, and we were strongly encouraged to do so. We were even expected to. (...) First of all, we were [instructed] to ask the person whether they wish for contact, 'may I touch you there?', because not everyone wants that. Sometimes someone says 'leave me alone' [laughs] and doesn't want that. Not to do it by force, do someone else's work for them, not to push, but only gently 
nudge, as if to suggest the right direction. And also to do it from a lower position, not to hover over someone and say 'now do this, now do that' [laughs]. That if someone is lying on the floor, or kneeling, not to hover over them, just do it from their own level. That's about it. But we were made aware of this and encouraged. ${ }^{4}$

Other coaches provided very different answers to the same question:

Actually, no. And if, I mean, it must have been discussed, since there was talk about this kind of distance, I don't remember exactly, $60 \mathrm{~cm}$ or so, that it exists. That we should be careful about touching, about too close proximity. I think that you have to feel it out maybe, if this person wishes to be touched or not. So this must have been discussed somehow, if distance was discussed. (...) But I don't think it was particularly emphasised. ${ }^{5}$

No. In my Pilates class the focus was more on verbal instructions. That is, to be able to explain clearly what someone is to do, and not how to touch them or instruct through touch. Which, for me, came as a surprise. ${ }^{6}$

According to official instructions, instrumental touch ought to serve very specific purposes; with the most importance attached to its corrective function. The use of touch may also help clients exercise better, learn new movements, and make them more aware of their own bodies.

The purpose of the above-described recommendations is to establish specific models of touching during Pilates classes. In Foucault's view, standardisation appears as an integral element of the process of normalisation-whereas normalisation consists in analysing processes, services, or products in order to provide: functionality, uniformity and exchangeability, security, and reduction of diversity (Foucault 1995: 184). The effectiveness of disciplinary power is largely dependent on these processes of normalisation. Attempts at standardisation and-consequentlyhomogenisation of the principles of touching others in Pilates, often justified with concerns about the health and safety of instructors and clients, are associated with the ongoing globalisation of fitness culture. Nevertheless, one should not disregard local aspects, which may contain models of heterogenisation and diversity, as they indubitably affect the manner in which touch is used in fitness gyms. One of the instructors admitted:

I think this is also something that stems from Western-European culture, where, in our case, it's a bit like this that very many people, especially, like, with a little bit higher position in the hierarchy, I mean, that if you get a bit higher in the hierarchy then maybe, for example, a teacher, yes, assumes that this gives them the power to touch you. (...) And this management of other people's bodies is much easier than in Western countries, because of social acceptance. And then, when you have an instructor that was brought up in a different culture, where you need consent for everything, for taking someone's hand, for nodding the head or something, well, then it's a bit different. They have a slightly more delicate approach to these things. (...) They need to know that you accept what they're about to do. Here, I haven't noticed that during courses taught by Polish instructors. ${ }^{7}$ 
Despite the progressing globalisation and standardisation of the policies of touch in fitness culture, the principles pertaining to touching others only reach their ultimate form in training practices in the local context. This means that the emergence and practical application of standards of physical contact between instructors and their clients in fitness gyms are influenced not only by the fitness industry, but also by the values, norms, and rules associated with touch in a given society.

\section{TOUCH, CONTROL,}

\section{AND PLAYING WITH POWER RELATIONS}

Some instructors use instrumental touch on other participants of group Pilates classes in order to control the operations of fitness bodies (through corrective practices). However, touch is not the only means of exercising disciplinary power in a fitness gym; other methods include, for instance disciplinary gaze (cf. Sassatelli 1999: 237-239). In practice, different disciplinary techniques are usually used simultaneously, to make them more effective in producing docile bodies. As noted above, instrumental touch during Pilates classes is usually initiated by the instructor, while the clients typically act as recipients of this touch. The instructor imbues the practices of touch with specific meanings that are circulated in the fitness room. It must, however, be noted that these meanings may be negotiated both by instructors and by other participants of fitness culture. The clients may or may not accept the instrumental touch; an issue which will be addressed in a later part of this subsection.

Most fitness instructors try to observe their clients during exercises, checking their stance and the accuracy of movements. The goal is to ensure the safety of each participant, but also to notice and correct any mistakes in order to prevent clients from developing inaccurate habits of movement. In the Foucauldian sense, instrumental touch used as a disciplinary technique facilitates the exchange of information, the stimulation of fitness bodies, and habituation to specific kind of motion.

First I try to correct verbally, of course, talking to the group, if I'm exercising with a group, that is. (...) Whereas sometimes, when I am explaining that a slight flexing of abdominal muscles is needed, so that the lumbar section doesn't sag in a four point kneeling position, then I usually come up to them and gently try to do it manually, position them, explain, if it's a new person. ${ }^{8}$

It should be noted that, according to the instructions presented above, 'touch should not be applied if the same effect can be achieved in another way'. This indicates the existence of a certain hierarchical order of applying disciplinary techniques with regard to fitness bodies; instrumental touch is not the first in that sequence:

This is simply a general rule that I try to talk to everyone first, I mean, if I see that something is wrong. I mean, even if it's only one person doing it wrong, I first address everyone, telling them what to check. And I don't say: 'Hey, fix this or that' but: 'Check if this or that is okay' or 'stretch your torso a little further' or 'check if your head is at the level the torso', or something like that. Then (laughs), then if I have time, because that's not always the case, you know this perfectly well yourself that you don't always have the time to come up to a given person. Especially if you know that one exercise is ending, another is beginning, 
so in a moment you will have to tell them what to do, and this one person is far away in the room, so sometimes there's no way. But I keep it in mind, to pay attention to what this person is doing with the next exercise. Then I come up and say. I repeat the instruction exactly. If this doesn't help, I try to demonstrate what I mean before I touch a given person. And before I touch them, I actually say 'okay, so I will now put my hand on your back', but I always try to look at that person's face, I mean, these people don't always look at me. Yes. And I always ask if this is okay. And in general they either nod or say it's okay, so that you know this is okay. Unless I know someone because they've been a regular [client]. ${ }^{9}$

Although fitness instructors employ a similar sequence of actions in their training practice, they do not always ask each of the participants for their permission to be touched. Sometimes they just touch them, especially if they are dealing with clients that have regularly attended their training sessions. This does not mean, however, that they never encounter any resistance. Asked whether a participant had refused to be corrected using touch, one instructor admitted:

Yes, but then I warned them they should find a different instructor. But I didn't do it in a rude manner. I always say that I touch people a lot. That if someone doesn't like it, they should tell me so. Very often people came up to tell me this individually, because they were ashamed. And I would say: 'Listen, let's do it this way. I will gradually come up to you. I will always keep some kind of safe distance. But one day I will simply have to touch you, just have to, because this way I am able to get your body to do its best. But if you are unable to overcome this, then you simply have to find a different instructor, because I will not be able to help you anymore. ${ }^{10}$

This example illustrates a specific type of relationality between the instructor and the other participants, and the asymmetrical nature of the power relations. It also indicates that these relations are fluid and may be broken at the instigation of either party.

It should be emphasised that theoretical recommendations regarding touch in Pilates are not always used by instructors in their everyday practice. Coaches usually develop their 'own' rules for touching. Naturally, these are rooted in the official instructions they received in the process of acquiring their professional identity yet working with clients in a gym allows them to intuitively 'discover' and test the effectiveness of each method and to modify them. To provide an example, one of my interlocutors mentioned that the master coach teaching the instructor course she attended advocated the following strategy: 'If a given person is given correction when exercising one side of the body, they should also be assisted with the other.' When asked why this should be done, the coach did not provide any logical explanation. One interlocutor stated:

I love such answers. I don't think so, because if you adjust someone's body on the one side, usually they will do the other side correctly, and meanwhile there is time for other people, which you can use to correct someone else's posture. ${ }^{11}$

Instrumental touch is associated with a fragmentary approach to the body (the whole consists of individual parts). It is directed towards specific sections of the body, applied 
locally and in a precise manner. It seems no coincidence that, during training, Joseph Pilates adjusted his students' position using a wooden stick, which served as an extension of his arm. On the one hand, he developed an effective skill in using an object through extending disciplinary power over his own body; on the other hand, the use of a stick during practice prevented him from touching his students' bodies directly (though, in practice, he did sometimes touch his trainees without the help of the stick). The choice to reinforce distance and reduce touch, or rather to employ it in a semi-tactile way, may be compared to the medical practices of touching patients with the stethoscope (Foucault 2003 [1966]: 203). Apart from reducing the touch itself, this mediated method of touching led to the development of professional authority of the person touching. In commercial fitness gyms, the option of using objects that could be described as 'disciplinary' (e.g. a stick) was eliminated. Consequently, instrumental touch became more 'humanised' and the physical distance between instructors and clients diminished. This being said, the principal role of instrumental touch has remained unchanged since the times of Joseph Pilates.

Interestingly, the instrumental touch practices employed in a fitness gym involve a remodelled system of punishment and gratification. In the context of recreational fitness, it is the latter that plays a much more significant role. Naturally, instrumental touch in itself is not a form of reward or punishment in the literal understanding of the terms and is not used to evaluate or exclude any group of fitness culture participants. The 'punishment' and 'gratification' stems from the fact that the instructor touches a participant only if they are executing specific motions in an inaccurate manner (the instruction in the form of touch is the remodelled punishment). The participant whom I interviewed stated:

This basically makes you give a little start, like, oh dear, I'm doing something wrong here. Because I was sure it was correct, but no, it was wrong. So you actually have to improve something. And this is needed. (...) A person then understands that something wasn't right. Because even if you are told that you have to do this or that, you can misunderstand, and a touch will actually correct you. ${ }^{12}$

Fitness instructors offered the following observations:

I mean, there's always been this rule that I don't correct immediately, because I don't want the new person to feel that they're not doing something as well as the others, because not everyone treats being touched, being corrected, in the same way. Some are glad, that they were noticed [smiles] (...) But some people feel extremely embarrassed, flustered. And you never know, unless you know a given person, if you're going to get the former or the latter reaction. ${ }^{13}$

I admit I am not the type of instructor that walks around the room correcting people. I don't do that. Again, this is probably due to my character. (...) I wasn't too fond of that, as a participant, when some instructors did that, so I don't subject others to it. Though I am aware that maybe some people would actually like it, that they expect it, or maybe need it. (...) For some people, perhaps, this would not be a problem, but I don't know this because I don't know the majority of the people 
in the room. Which is why I don't want to come up to a specific person not to, you know, simply not to intimidate them, not to single them out for not doing something the right way. Unless, as I said, it's really very bad. So I tend to keep my distance, simply talking all the time, trying to explain as best as I can, and performing the exercise myself as correctly as I can. ${ }^{14}$

The clients that are exercising correctly are not touched by the instructor. This lack of touch acts as a kind of positive reinforcement (a remodelled 'praise'), signalling that nothing requires adjustment and a given person is moving in a correct fashion.

However, the relations within the remodelled system of punishment and gratification are much more complex, as they are not limited to a single level. On one level, some fitness culture participants regard instrumental touch as a kind of commercial 'service', the purchase of which requires specific resources-namely a membership card in a fitness centre-which means that access to it is restricted. The legitimisation of instrumental touch finds corroboration in both academic knowledge (e.g. medicine, physiotherapy) and in the practical experience of instructors applying the technique. From another perspective, in which instrumental touch is understood as a manifestation of the instructor's special attention to the person exercising, the lack of touch may cause participants to feel dissatisfied, anxious, or neglected. On yet another level, the meaning of the system of remodelled punishment and gratification is shifted (if not utterly reversed), since touch is regarded as a positive and desired sign, as something the clients expect to experience. In this context, the fact whether a coach uses instrumental touch affects the trainees' mood, their participation in the class, and their image of what a 'good' instructor ought to do. This is when the beneficial effects of disciplinary power become apparent; effects that are rarely discussed in works pertaining to fitness culture. Asked whether she considers correcting through touch necessary, one participant answered:

Yes, of course. Very much so. I am grateful for these things. I would expect it, because from the front it may seem to me that I'm doing the exercise correctly, and I don't see that my shoulders should go in a different [direction]..$^{15}$

Ethnographic studies indicate that many women participating in Pilates classes do not mind being corrected through touch during training. One client stated: '[It's] good, good. I feel so safe then, knowing that I won't do any harm to myself, that I'm doing the exercise right. I am pleased. ${ }^{16}$ Nevertheless, this is not a universal rule. Some clients do not like to be touched during exercising and only allow this method of correction under certain conditions and to a very limited degree:

It bothers me, if it is sudden. (...) If it really happens in situations in which it's necessary, I can live with it. (...) I prefer [the instructor] to explain this to me, or, alternatively, ask me whether she can demonstrate it or touch me. I certainly don't like to be surprised. (...) This is, after all, a stranger. I am not in the habit of liking to be suddenly touched by strangers. ${ }^{17}$

At the same time, however, some women do not consider instructors to be obliged to ask permission every time they wish to touch a client. One interlocutor offered the following opinion on the issue: 'No, absolutely not. Unless it was 
a man (laughs). ${ }^{18}$ Another client I interviewed, asked if an instructor should always request permission to touch a person who is exercising, replied:

In theory, probably yes, but the reason people come to classes is to do exercises correctly. For me this clearly implies that an instructor may touch you. If someone doesn't want that, they should say they don't. ${ }^{19}$

However, the clients' attitude towards the matter was not uniform:

You know what, it depends on what she is correcting. Or not even that. I think that this should be communicated somehow. The fact that Eve [the client's instructor] asks (...) this is very kind and very cool. And I think that many people will open up to this, in some way. This is a question of some personal impression, a feeling that this is important. But there's also this other thing, namely that I don't like to be coerced into anything, or surprised. I don't want to feel stressed when I'm headed for classes (...) So some form of consent from the person should be there. ${ }^{20}$

This example illustrates how the official recommendations regarding touch in Pilates may be negotiated and modified by class participants in their everyday practice.

The results of ethnographic studies suggest that some instructors inform their clients at the beginning of the first class that if they do not wish to be touched, they should not be afraid to say so. However, such information is not always given, and it is likely that not all clients are aware that they could communicate their reluctance to be touched to the instructor beforehand and without providing any explanation. The clients' objection to receiving instrumental touch may be verbal or nonverbal (e.g. a dissatisfied expression), intentional or non-intentional, stemming from the resistance put up by the body. When asked about how she reacts if a participant's body resists to being instructed by touch (and thus cannot be coaxed into the correct position), one interlocutor explained:

Truth be told, this is the greatest conundrum, because, well, gee, with individual classes it's great, 'cause you have lots of time and you can use it as you wish, right. But with group classes it's like, well, if I feel this resistance, I sometimes give up and say 'okay, continue like this' and usually I know that I won't correct this the first time around. But it's always like this that for me it is always a kind of a challenge, until the class is through I keep thinking about what could have been done, how else to describe what to do. And I observe this person doing other exercises thinking that maybe there will be a moment where he or she will have the same motion to perform and won't even know that he or she did it. ${ }^{21}$

Later in the interview she added:

But there are also people who switch off. In the sense that their head switches off somewhat, which has its advantages because this is one of the reasons why they come to these classes, right, but they don't react at all. In the sense that they react when I am near them, but then continue exercising as they were before. ${ }^{22}$ 
The different forms of objecting to instrumental touch used by clients illustrate how the instructors and the other participants play with power relations in the fitness gym and how clients can exercise their power.

\section{RELATIONALITY AND INSTRUMENTAL TOUCH}

Every touch exists in relation to something. 'Touch is our most social sense. Unlike seeing, hearing, smelling, and tasting, which can generally be done alone, touching typically implies an interaction with another person' (Field 2014: 19). In such an interpretation, the instrumental touch between an instructor and an exercising person is a part of a specific type of relation, one that shall in the present article be referred to as 'professional'. This definition is at variance to the observations made by Mark Paterson (2007: 2-3) that 'touch can cement an empathic or affective bond, opening an entirely new channel of communications', and Erin Manning:

Through the tango, I have attempted to make the point that touch is not simply the laying of hands. Touch is the act of reaching toward, of creating space-time through the worlding that occurs when bodies move. Touch, seen this way, is not simply an addendum to an already-stable body. (2007: xiv)

According to the above, touch is a significant element of human relations and as such has the potential to forge bonds and consequently facilitate closeness and intimacy. In the professional relations between instructors and the people participating in their fitness classes, however, touch is not employed with the aim of forming bonds, but of controlling the operations of fitness bodies through instruction. In the context of recreational fitness, recommendations pertaining to using touch are issued for the very purpose of minimising the risk of forming bonds and facilitating intimacy, as well as neutralising the pleasurable aspects of touch. In a scenario where one person's body is touched by another person, physical closeness is generally inevitable. In order to reduce the feeling of intimacy and the potential sexual connotations of the act of touch, the staging of intimacy in a fitness room has been given a culturally bound significance. This is not to mean that social norms regarding intimacy and sexuality are never negotiated or infringed on.

For touch to become an efficient 'instrument' through which disciplinary power can operate in a fitness room, strategies must be employed to neutralise its impact. Examples include the consistent use of professional vocabulary in describing the specific groups of muscles that are being touched, or the emphasis on limiting instrumental touch to the body parts that are moving in an incorrect fashion. In the course of acquiring their professional identity, fitness instructors develop a specific approach in which the bodies of the exercising people are regarded as external objects. In the context of recreational fitness, the instructors' 'right' to touch the bodies of their clients is perceived similarly to the doctors' right to touch their patients' bodies.

I approach this in a very, I don't know how to put it accurately. For me this is not touch, as in, not like when I'm touching acquaintances. In a way, I'm separating the bodies of these people and their images, as they enter the room, and to me they are maybe like to a doctor, they are simply bodies that ought to be working in a certain way. And they can be my acquaintances 
once the class is over. They can be my clients whom I like very much and whom I can hug, and this is a completely different touch. ${ }^{23}$

Incidentally, I have always been explaining that this is a bit like with a gynaecologist, a dentist, a masseur. I mean, when you go to a dentist, they touch you. When you go to a gynaecologist, they also touch you. So I've also kept saying 'Imagine that I am touching you in a more medical way. ${ }^{24}$

Thus, instrumental touch does not function outside of, but only within specific kinds of relations, referred to here as 'professional', as they are based on constant emphasis on their strictly professional character. Relations of this kind inherently involve strategies for reducing physical closeness to the minimum, avoiding affective engagement, and also providing objectively high-quality services.

Another key feature affecting professional relations between instructors and their clients is the fact that they are constructed in the context of recreational fitness. The context determines the aims of engaging in physical activity set by participants of fitness culture. While indubitably distinct from informal and spontaneous forms of leisure, fitness culture is often described as 'rational recreation' (Sassatelli 2015). Due to this recreational context, the relations that form between fitness instructors and their clients in the fitness room differ from, for instance, those observable between coaches and athletes in professional sport. The essential focus of physical recreation is not on maximising performance and winning competitions, but on keeping active (though, it must be added, this is not the only aim of these activities). The goals determined by this recreational context affect the nature of professional relations between instructors and their clients, and consequently, also the methods of correcting the latter's motions. One of the coaches explained her attitude towards her role as an instructor thusly:

I actually wonder about the term instructor, because I don't regard myself as an instructor, but rather as a guide or a teacher. Because while I do give instructions, these are not the typical kind, you know what I mean. The thing is, you can be very good at something, like, you can be a great gymnast, or a great biologist, but be totally unable to teach others the things you can do. And it's precisely the same with this, you can be very skilled, perform each exercise perfectly and have completely no idea how to teach people to do these exercises. And there are people who are masters at something, and there are teachers, who teach how to do this something. ${ }^{25}$

Instrumental touch in Pilates is not meant to be used to force people to perform exercises or go beyond the limitations of their bodies. Correction through instrumental touch only acts as 'guidance' that helps fitness culture participants exercise better and ensure that they are safe when doing so. At the same time, however, the use of instrumental touch may discourage clients from engaging in physical activity as such. Thus, the required 'dose' of touch during Pilates classes is much smaller than in the case of training done by professional athletes or dancers, if not eliminated at all.

\section{CONCLUSION}

The aim of the present analysis was to present the complexity of the relations between Michel Foucault's concept of anatomo-political power and the instrumental touch applied during 
Pilates classes. The research indicates that in the context of recreational fitness instrumental touch as a disciplinary technique is employed in the process of producing docile bodies, and that the power relations between instructors (who, as a rule, are the ones to initiate instrumental touch) and their clients (who receive it) are complicated and negotiated on an ongoing basis.

While instrumental touch facilitates the emergence of docile fitness bodies, it would be a mistake to think that participants of Pilates classes regard it solely as an 'instrument' used to control them. Both instructors and clients training in commercial fitness gyms recognise instrumental touch as beneficial, perceiving this disciplinary technique as an 'asset', one of the means used by instructors to express care and attention, and also a mark of the coaches' professionalism. These are positive experiences associated with disciplinary power, which operates through touch and within power relations (not outside of them). The beneficial effects of disciplinary power are rarely discussed in academic works on fitness culture. The results of the present study also suggest that participants of Pilates classes are not entirely passive in their attitudes towards the disciplinary techniques that are being used on them. This means that fitness rooms contain not only docile bodies, but rather fitness bodies who respond to instrumental touch in an active and versatile manner. Consequently, the effects of anatomo-political power in the recreational fitness context are not fully predictable, but oscillate around a number of potential outcomes.

\section{NOTES}

1 I would like to thank the anonymous reviewers for their insightful comments to this paper. Any errors are my own. The research was funded by the National Science Center Grant No. UMO2018/29/B/HS3/01563, within the project 'Through body in motion. Anthropological study of embodied experiences and identity transition of female fitness culture participants.'

2 Interview with Eve, age 43, a fitness instructor, September 20, 2020.

3 Ibid.

4 Interview with Yolande, age 46, a fitness instructor, September 7, 2020.

5 Interview with Sandra, age 40, a fitness instructor, October 1, 2020.

6 Interview with Eve, age 43, a fitness instructor, September 20, 2020.

7 Ibid.

8 Interview with Doris, age 35, a fitness instructor, May 13, 2020.

9 Interview with Eve, age 43, a fitness instructor, September 20, 2020.

10 Interview with Carolyn, age 35 , a fitness instructor, May 15, 2020.

11 Interview with Eve, age 43, a fitness instructor, September 20, 2020.

12 Interview with Christina, age 89, a fitness client, October 5, 2020.

13 Interview with Eve, age 43, a fitness instructor, September 20, 2020.

14 Interview with Sandra, age 40, a fitness instructor, October 1, 2020.

15 Interview with Sarah, age 50, a fitness client, September 4, 2020.

16 Interview with Diana, age 46, a fitness client, September 24, 2020.

17 Interview with Nathalie, age 39, a fitness client, March 19, 2019.

18 Interview with Christina, age 89, a fitness client, October 5, 2020.

19 Interview with Roberta, age 43, a fitness client, October 12, 2020.

20 Interview with Laura, age 44, a fitness client, April 1, 2020.

21 Interview with Eve, age 43, a fitness instructor, September 20, 2020.

22 Ibid.

23 Ibid.

24 Interview with Carolyn, age 35, a fitness instructor, May 15, 2020.

25 Interview with Eve, age 43, a fitness instructor, September 20, 2020. 


\section{REFERENCES}

Andreasson, Jesper and Thomas Johansson 2014. The Global Gym: Gender, Health and Pedagogies. Hampshire: Palgrave Macmillan.

https://doi.org/10.1057/9781137346629.

Aoki, Doug 1996. Sex and Muscle: The Female Bodybuilder Meets Lacan. Body E Society 2 (4): 5974. https://doi.org/10.1177/1357034X96002004004.

Brighton, James, Ian Wellard and Amy Clark 2021. Gym Bodies: Exploring Fitness Cultures. London and New York: Routledge.

https://doi.org/10.4324/9781315619491.

Channon, Alex 2013. The Rules of Engagement: Negotiating Painful and 'Intimate' Touch in MixedSex Martial Arts. Sociology of Sport Journal 30: 487503. https://doi.org/10.1123/ssj.30.4.487.

Chase, Laura 2006. (Un)Disciplined Bodies: A Foucauldian Analysis of Women's Rugby. Sociology of Sport Journal 23 (3): 229-247.

https://doi.org/10.1123/ssj.23.3.229.

Clark, Marianne I. and Pirkko Markula 2017. Foucault at the Barre and Other Surprises: A Case Study of Discipline and Docility in the Ballet Studio. Qualitative Research in Sport, Exercise and Health 9 (4): 435-452.

https://doi.org/10.1080/2159676X.2017.1309451.

Classen, Constance 1993. Worlds of Sense: Exploring the Senses in History and Across Cultures. London: Routledge.

Classen, Constance (ed.) 2005. The Book of Touch. Oxford: Berg.

Classen, Constance, David Howes and Anthony Synott 1994. Aroma: The Cultural History of Smell. London: Routledge.

Creswell, John 2007. Qualitative Inquiry and Research Design. Thousand Oaks, CA: Sage.

Czarnecka, Dominika 2020. Autoetnografia: jej odmiany, atuty, ograniczenia i przydatność $w$ badaniach dotyczących kultury fizycznej (Autoethnography: Its Variations, Advantages, Limitations, and Appropriability in Physical Culture Research). In Dagnosław Demski, Jarosław Derlicki and Anna Woźniak (eds). Antropologiczne wędrówwi po "miejscach" bliskich i dalekich. Ksiega jubileuszorwa dla
Profesor Iwony Kabzinskiej (Anthropological Journeys through Near and Far Places. Jubilee Publication for Professor Iwona Kabzińska). Warszawa: Wydawnictwo IAE PAN.

Czarnecka, Dominika 2021. 'Stay Fit to Fight the Virus': Ethnographies of Change in the World of Fitness Instructors (Selected Case Studies). In Jörg Krieger, April Henning, Lindsay Parks Pieper and Paul Dimeo (eds). Time Out: National Perspectives on Sport and the Covid-19 Lockdown. Champaign, US: Common Ground.

Downey, Greg 2005. Learning Capoeira: Lessons in Cunning from an Afro Brazilian Art. Oxford: Oxford University Press.

European Health \& Fitness Market 2019. Blisko 3 miliony Polaków korzysta z klubów fitness (Nearly 3 Million Poles Attend Fitness Clubs), April 10, 2019. https://www2.deloitte.com/p1/pl/pages/pressreleases/articles/blisko-3-miliony-polakowkorzysta-z-klubow-fitness.html. <accessed 13 September 2020>

Falzon, Mark A. (ed.) 2016. Multi-sited Ethnography: Theory, Praxis and Locality in Contemporary Research. London and New York: Routledge. https://doi.org/10.4324/9781315596389.

Field, Tiffany 2014. Touch. Cambridge, MA: MIT Press.

Foucault, Michel 1995 [1975]. Discipline and Punish: The Birth of the Prison. Translated by Alan Sheridan. New York: Vintage Books.

Foucault, Michel 2003 [1963]. The Birth of the Clinic. Translated by Alan Sheridan. London: Routledge. https://doi.org/10.4324/9780203406373.

Foucault, Michel 2010 [1976; 1984]. Historia seksualności. Tom 1-3 (The History of Sexuality. Volumes 1-3). Translated by Bogdan Banasiak, Tadeusz Komendant and Krzysztof Matuszewski. Gdańsk: Wydawnictwo słowo / obraz terytoria.

Glaser, Barney and Anselm Strauss 1967. The Discovery of Grounded Theory. London: Weidenfeld and Nicholson.

Green, Harvey 1986. Fit for America: Health, Fitness, Sport and American Society. Baltimore, MD: Johns Hopkins University Press. 
Greif, Mark 2017. Against Everything: On Dishonest Times. London and New York: Verso.

Hall, Edward T. 1963. A System for the Notation of Proxemic Behavior. American Anthropologist 65 (5): 1003-1026.

https://doi.org/10.1525/aa.1963.65.5.02a00020.

Hamilton, Sheryl N. 2017. Rituals of Intimate Legal Touch: Regulating the End-of-Game Handshake in Pandemic Culture. The Senses and Society 12 (1): 53-68.

https://doi.org/10.1080/17458927.2017.1268821.

Hammersley, Martyn and Paul Atkinson 1995. Ethnography: Practices and Principles. Second Edition. New York: Routledge.

Hanold, Maylon 2010. Beyond the Marathon: (De)Construction of Female Ultrarunning Bodies. Sociology of Sport Journal 27 (2): 160-177.

https://doi.org/10.1123/ssj.27.2.160.

Hedblom, Christina 2009. 'The Body is Made to Move: Gym and Fitness Culture in Sweden. Stockholm: Acta Universitatis Stockholmiensis.

Hockey, John and Jacquelyn Allen-Collinson 2007. Grasping the Phenomenology of Sporting Bodies. International Review for the Sociology of Sport 42 (2): 115-131.

https://doi.org/10.1177/1012690207084747.

Howes, David 2003. Sensual Relations: Engaging in Cultural and Social Theory. Ann Arbour: University of Michigan Press.

https://doi.org/10.3998/mpub.11852.

Howes, David (ed.) 2005. Empire of the Senses: The Sensual Culture Reader. London and New Delhi and New York and Sydney: Bloomsbury.

Jakubowska, Honorata 2017. Skill Transmission, Sport and Tacit Knowledge: A Sociological Perspective. London and New York: Routledge.

https://doi.org/10.4324/9781315267043.

Juś, Monika 2020. Siłownie, kluby fitness i baseny już otwarte: Nowe zasady bezpieczeństwa. Są wytyczne. Co z karnetami Zdrofit, CityFit, Calypso, S4? (Gyms, Fitness Clubs and Pools Already Open: New Safety Regulations. The guidelines Are Out. What about the Zdrofit, CityFit, Calypso, S4 Membership Cards). https://polskatimes.pl/silownie-kluby-fitness-ibaseny-juz-otwarte-nowe-zasady-bezpieczenstwasa-wytyczne-co-z-karnetami-zdrofit-cityfitcalypso-s4/ar/c2-14964248. <accessed 14 June 2020>

Kunicki, Bogdan 1997. Przeobrażenia rekreacji ruchowej (Transformations of Physical Recreation). In Krzysztof W. Janikowski and Zbigniew Krawczyk (eds). Przeobrażenia kultury fizycznej w krajach Europy Srodkowej i Wschodniej (Transformations of Physical Culture in the Countries of Central and Eastern Europe). Warszawa: Akademia Wychowania Fizycznego Józefa Piłsudskiego w Warszawie.

Lewis, Neil 2000. The Climbing Body, Nature and the Experience of Modernity. Body E Society $6(3-4): 58-60$.

https://doi.org/10.1177/1357034X00006003004.

Manning, Erin 2007. Politics of Touch: Sense, Movement, Sovereignty. Minneapolis: University of Minnesota Press.

Markula, Pirkko 1995. Firm but Shapely, Fit but Sexy, Strong but Thin: The Postmodern Aerobicizing Female Bodies. Sociology of Sport Journal 12: 424-453. https://doi.org/10.1123/ssj.12.4.424.

Markula, Pirkko 2001. Beyond the Perfect Body: Women's Body Image Distortion in Fitness Magazine Discourse. Journal of Sport and Social Issues 25: 158179. https://doi.org/10.1177/0193723501252004.

Markula, Pirkko 2004. 'Tuning into One's Self': Foucault's Technologies of the Self and Mindfull Fitness. Sociology of Sport Journal 21: 302-321. https://doi.org/10.1123/ssj.21.3.302.

Markula, Pirkko and Richard Pringle 2006. Foucault, Sport and Exercise: Power, Knowledge and Transforming the Self. London: Routledge.

McKay, Jim 1994. Embodying the 'New' Sporting Woman. Hecate 20 (1): 53-68.

Mizińska, Jadwiga 2010. Homo tangens-człowiek dotykający i dotykany (Homo Tangens: Touched and Touching Man). In Andrzej Kapusta and Jadwiga Mizińska (eds). Homo tangens: ciato $i$ dotyk (Homo Tangens: Body and Touch). Toruń: Wydawnictwo Adam Marszałek. 
Paterson, Mark 2007. The Senses of Touch: Haptics, Affects and Technologies. Oxford and New York: Berg.

Pilates, Joseph H. and William J. Miller 1960. Return To Life Through Contrology. Boston: The Christopher Publishing House.

Pilates Polska 2019. Początki Pilatesu w Polsce (The Beginnings of Pilates in Poland).

https://pilatespolska.pl/poczatki-pilatesu-w-polsce/. <accessed 11 September 2020>

Pink, Sarah 2009. Doing Sensory Ethnography. London: Sage.

https://doi.org/10.4135/9781446249383.

Ram, Uri 2004. Glocommodification: How the Global Consumes the Local-McDonald's in Israel. Current Sociology 52 (1): 11-31.

https://doi.org/10.1177/0011392104039311.

Rojek, Chris 2000. Leisure and Culture. Basingstoke: Palgrave Macmillan.

https://doi.org/10.1057/9780230287563.

Sassatelli, Roberta 1999. Interaction Order and Beyond: A Field Analysis of Body Culture within Fitness Gyms. Body E Society 5 (2-3): 227-248. https://doi.org/10.1177/1357034X99005002013.

Sassatelli, Roberta 2000. The Commercialization of Discipline: Fitness and Its Values. Journal of Italian Studies, Special Issue on Sport 9 (4): 332-349.

Sassatelli, Roberta 2011. Fitness Culture: Gym and the Commercialisation of Discipline and Fun. New York: Palgrave Macmillan.

https://doi.org/10.1057/9780230292086_6.

Sassatelli, Roberta 2015. Healthy Cities and Instrumental Leisure: The Paradox of Fitness Gyms as Urban Phenomena. Modern Italy 20 (3): 237-249. https://doi.org/10.1080/13532944.2015.1065239.

Slavin, Sean 2003. Walking as Spiritual Practice: The Pilgrimage to Santiago de Compostela. Body \& Society 9 (3): 1-18.

https://doi.org/10.1177/1357034X030093001.
Smith Maguire, Jennifer 2007. Fit For Consumption: Sociology and the Business of Fitness. London: Routledge. https://doi.org/10.4324/9780203940655.

Sparkes, Andrew 2016. Ethnography as a Sensual Way of Being: Methodological and Representational Challenges. In Gyozo Molnar and Laura G. Purdy (eds). Ethnographies in Sport and Exercise Research. Abington: Routledge.

Spielvogel, Laura 2003. Working Out in Japan: Shaping the Female Body in Tokyo Fitness Clubs. Durham and New York: Duke University Press. https://doi.org/10.1515/9780822384809.

Stebbins, Robert A. 2009. Serious Leisure and Work. Sociology Compass 3 (5): 764-774.

https://doi.org/10.1111/j.1751-9020.2009.00233.x.

Steen-Johnsen, Kari 2007. Global Fitness in the Norwegian Context: The Perfect Meets the Popular. International Review for the Sociology of Sport 42 (3): 343-362.

https://doi.org/10.1177/1012690207088112.

Vannini, Phillip, Dennis Waskul and Simon Gotschalk 2012. The Senses in Self, Culture, and Society. Oxford and New York: Routledge. https://doi.org/10.4324/9780203805985.

Volkwein, Karin (ed.) 1998. Fitness as a Cultural Phenomenon. New York: Waxmann Můnster.

Wacquant, Loïc 2004. Body and Soul: Notebooks of an Apprentice Boxer. New York: Oxford University Press.

Young, Iris M. 2005. On Female Bodily Experience: 'Throwing Like a Girl' and Other Essays. Oxford: Oxford University Press.

https://doi.org/10.1093/0195161920.003.0003.

DOMINIKA CZARNECKA

ASSISTANT PROFESSOR

CENTRE FOR ETHNOLOGY AND

CONTEMPORARY ANTHROPOLOGY

INSTITUTE OF ARCHAEOLOGY AND

ETHNOLOGY

POLISH ACADEMY OF SCIENCES

d.czarnecka@hotmail.com 